\title{
Spatial segregation,
} employment and poverty in Montevideo

\author{
Rubén Kaztman and Alejandro Retamoso
}

$\mathrm{T}$

his article looks at two processes that are affecting the characteristics of poverty in the city of Montevideo: the weakening of lower-skilled workers' attachments to the labour market and the growing concentration of such workers in neighbourhoods with a high density of poverty. While far from conclusive, the results suggest the advisability of further research into the relationship between changes in the social morphology of cities and the segmentation of their labour markets. If further research confirms both a tendency towards growing polarization in the spatial distribution of social classes in cities and the presence of feedback mechanisms reinforcing the social isolation of residents in the most disadvantaged neighbourhoods, it will be safe to say that these

Rubén Kaztman

Director of the Programa de Investigación sobre Integración,

Pobreza y Exclusión Social (IPES)

Universidad Católica de Uruguay

• kaztman@adinet.com.uy

Alejandro Retamoso

Associate Researcher at IPES,

Universidad Católica de Uruguay

- aretamo@ine.gob.uy processes, if not effectively countered, will irreversibly widen the already excessive inequalities that affect large Latin American cities. 


\section{Introduction: employment, spatial concentration and the entrenchment of urban poverty}

Among Latin American cities, Montevideo has been distinguished by its relatively low levels of inequality and poverty. This record was badly tarnished during the period of military government, but for a decade after 1985, when democracy was restored, the social structure of the city moved back towards what it had been in the past. In particular, the percentage of households below the poverty line declined continuously (figure 1).

In the mid-1990s, however, this trend was reversed. From then until 2001 the poverty indices rose slightly, and then the financial crisis of 2002 triggered a sharp increase. The result was that by 2003 about a fifth of households in the Uruguayan capital were poor.

The current rise in poverty has been associated with a significant change in its characteristics. There has been a marked weakening of the attachments that the less skilled are able to forge with the labour market, as manifested by high unemployment, insecure and substandard working conditions and low pay, while the gap between such workers and the higher-skilled has widened in all these respects (Kaztman, 2002; Amarante, Arim and Vigorito, 2004). Since these tendencies derive from key aspects of the new accumulation pattern, they indicate that poor households will find it increasingly difficult to move out of poverty.

Numerous studies carried out in Uruguay show that most of the variations in the levels and composition of poverty are due to changes in the labour market. ${ }^{1}$ Without ignoring the strength of this causal relationship, the results of a number of recent research projects suggest that it would be wise to broaden the framework of interpretation to include the profound changes affecting the social fabric of the city. These changes, while less visible than those in the labour market, are weakening the mechanisms that can be

\footnotetext{
${ }^{1}$ The outcome of the 1989 plebiscite on the index-linking of pensions also had a major impact on the poverty trend. The plebiscite resulted in the passing of a constitutional amendment index-linking payments to retirees to quarterly wage increases, application of which has resulted in large rises in pensions.
}

credited with enabling many households to escape from poverty over the course of the twentieth century. The changes referred to are growing segmentation in the quality of the services (health, education, housing) available to the different social classes, and the increasing concentration of poor households in urban areas.

The latter phenomenon is attracting the attention of the social sciences in the region. Building on a tradition initiated by a seminal article of Park's (1926), there is a growing interest in systematic exploration of the ways urban poverty is hardened and perpetuated by spatial concentration. ${ }^{2}$ This "residential segregation" approach, which has given rise to a large number of academic studies, attaches great importance to the effect that the social environment of residential areas has on the prospects of poor households and individuals improving their living conditions. Neighbourhoods are seen as ecological contexts that intervene between people and the most important sources of physical, social and human assets in the market, the State and the community. This takes place in two main ways. Firstly, through a progressive narrowing of the spheres of interaction with other social classes, and secondly, through a widening of the differences between poor neighbourhoods and the other parts of a city, in terms of the quality of services and institutions. According to this approach, living in neighbourhoods with a high concentration of poverty creates large additional disadvantages on top of those that, in production structures that are increasingly organized around knowledge, derive from the low relative skills of residents.

\footnotetext{
${ }^{2}$ As well as making very valuable contributions to the measurement of residential segregation in the Latin American countries, a recent paper by Rodríguez and Arriagada (2004) provides a detailed review of studies dealing with this issue in Latin America and identifies the most promising lines of research for future progress in this area. Jencks and Mayer (1990) and Sampson, Morenoff and GannonRowley (2002) offer an exhaustive review of the United States literature dealing with neighbourhood effects on different types of behaviour.
} 
FIGURE 1

Montevideo: Unemployment and percentage of households below the poverty line, 1986-2003

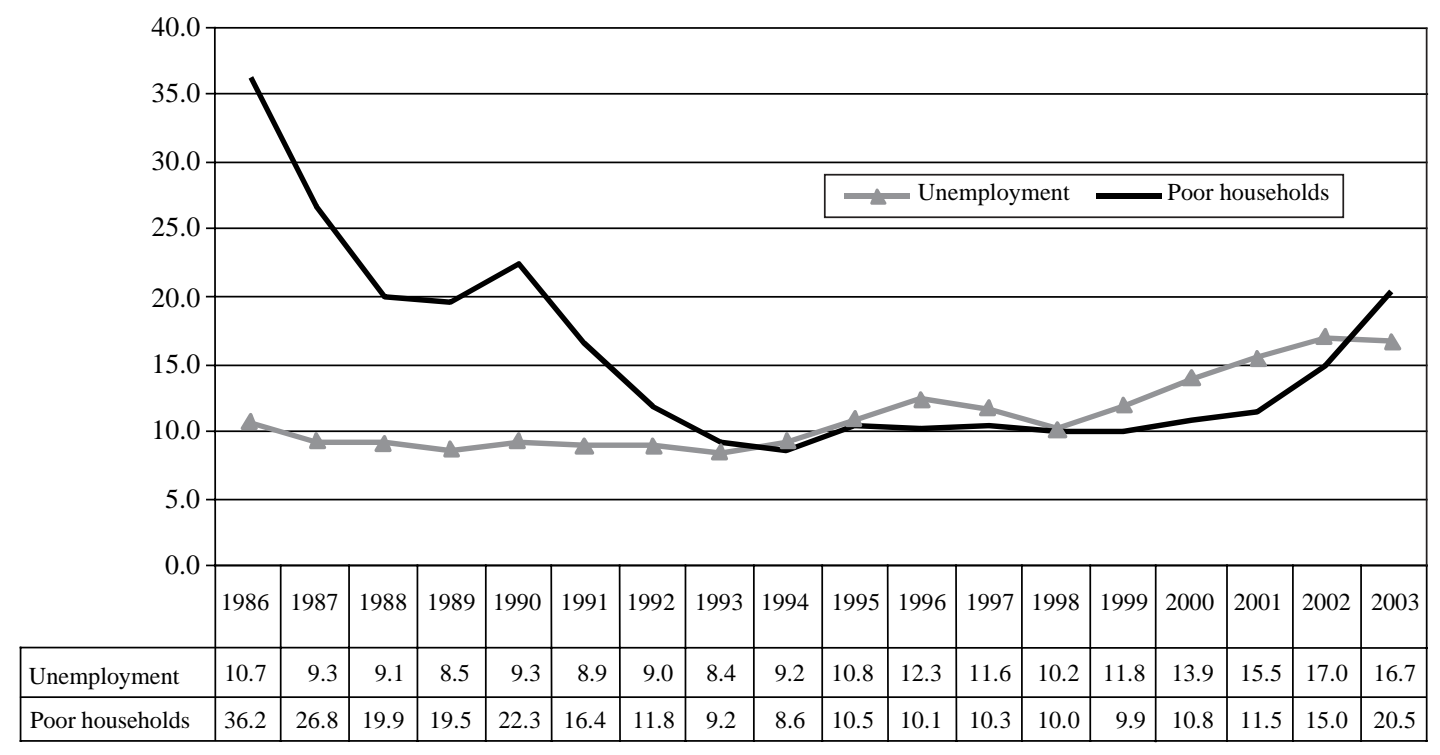

Source: Prepared by the authors using data from the Uruguayan National Institute of Statistics (INE).

While it is too soon to reach firm conclusions, the results of the studies undertaken using this approach are enough to show that by considering labour market changes in conjunction with the spatial segregation of social classes, a better understanding can be reached both of the changes that are occurring in the nature of urban poverty and of some central aspects of inequity in urban social structures.

The following sections of this article will look at the evidence now available on the tendency towards spatial concentration of the poor in Montevideo. It will touch on the results of studies dealing with employment and, in particular, with changes in the situation of the least skilled in the labour market. It will analyse the relationship between the two phenomena, emphasizing the less studied and less well known side of this, namely neighbourhood effects on residents' labour market attachments. Lastly, it will draw some conclusions about the role that segregation may be playing in the prospects for achieving higher levels of equity in the social structure of the city.

Since the concern of this study is to examine and discuss long-term structural processes, we have sought to avoid periods clearly affected by particular crisis situations like the one that Uruguay underwent in the closing years of the last century and, particularly, the one that was triggered in early 2002. For this reason, the body of evidence that will be used to test the consistency of the conceptual framework adopted will be limited to the final decade of the twentieth century.

\section{II}

\section{Spatial segregation in Montevideo}

The tables that follow draw on various indices to show the changes affecting the spatial distribution of social classes in Montevideo between the 1980s and the 1990s. Table 1 reveals a significant increase in homogeneity in the social composition of neighbourhoods, something that is reflected in the Duncan indices of residential segregation and dissimilarity for households as classified by different social status and living condition 
variables. ${ }^{3}$ A rising geographical concentration of people with similar living conditions is observed in indicators of household income, educational level, employment and occupational status of household heads. These results are consistent with other measurements (Kaztman, 1999; Pellegrino, Macadar and others, 2002).

Although poverty was reduced significantly in all areas of Montevideo during the 1980s and 1990s, during that period the tendency for low-income families to concentrate in the poorest neighbourhoods was greatly accentuated. Thus, as table 2 shows, in the three most deprived zones (or groups of neighbourhoods) in the city, concentration rose from $65 \%$ of the city's poor residents to $78 \%$, and from $78 \%$ of its indigent residents to $84 \%$. At the same time, these neighbourhoods, which are on the outskirts of the city, also increased their share of the total population.

The conclusion that can be drawn from table 3 is that the neighbourhoods which displayed higher demographic growth were those with a lower initial density, and that this development was mainly due to movements from the central to the peripheral areas of the city. Here, attention should be drawn to the large increase in informal settlements which, while they started to emerge with the economic crises of the 1970s and 1980s, really began to expand with the return of democracy in 1985.

The picture is completed by the data of table 4, which show that the neighbourhoods gaining population were the very ones that displayed the most disadvantageous social characteristics, i.e., a high density of needy households and a large incidence of risk factors. At the same time, there were also population shifts among the middle and higher classes towards the neighbourhoods in the east of the city. As the physical distance between the classes thus increased, Montevideo began to display a level of spatial segregation already familiar to other large Latin American cities.

\footnotetext{
3 The Duncan dissimilarity index is a synthetic indicator of the relationship between the composition of territorial subunits (social, workforce, racial, etc.) and the social composition of the larger territorial unit (city or urban conglomeration). If the two differ in composition then residential segregation exists, since the distribution of social groups among the territorial subunits is out of line with their representation in the city or larger conglomeration as a whole. The measurement ranges from 0 (zero segregation) to 100 (total segregation where no subunit has a mixed composition). However, the residential segregation index used in this study indicates the proportion of the total variance accounted for by the variance between territorial subunits.
}

\section{What is new about today's urban residential segregation?}

Despite the tendencies referred to, it could be argued that in the history of Montevideo during the twentieth century there were always clear differences in the location of social classes within the city. At least three possible objections can be made to this argument, and they relate to both the quantitative and the qualitative dimensions of the phenomenon.

The first objection stresses differences in the extent of the phenomenon and the implications that its intensification has for homogeneity in the social composition of neighbourhoods. In other words, without denying that spatial segregation already existed in the city, the point made is that this segregation is now much more marked than formerly.

The second objection is based on the fact that residents in the uniformly poor neighbourhoods of the city are now less integrated with the rest of urban society than in the recent past, when their attachments to the labour market were stronger, more stable and better protected and they more closely resembled what Castel called "the salaried society". In Montevideo, in fact, neighbourhoods with a high density of industrial workers were quite homogeneous in their composition. But that was a "virtuous" homogeneity in which there was a harmony between neighbourhood life and the world of the factory, as manifested by a local sociability and institutional density that strengthened the bonds of solidarity forged in both. In the new types of poor neighbourhood, by contrast, the greater fragility of occupational attachments and the greater density of need resulting from this are restricting both the formation of reciprocity networks and the opportunities for creating and maintaining home-grown neighbourhood institutions, all of which tends to weaken the social fabric of the community.

The third objection has to do with disparities in the frame of reference that residents of poor neighbourhoods use to evaluate their situation. The makeshift households that were established on the outskirts of the city in the 1950s were the result of population movements from the countryside or small towns. Many migrants underwent this change in the expectation of improving their quality of life, both through the symbolic conquest of urban citizenship and actual access to a far greater variety of consumption and services than were available in their places of origin, and through the employment opportunities offered at that time by the growth of domestic markets, 
TABLE 1

Montevideo: Residential segregation index (RSI) and neighbourhood dissimilarity index

\begin{tabular}{lccc}
\hline Variable & Indicator & 1986-1987-1988 & 1996-1997-1998 \\
\hline Per capita household income & RSI & 16.36 & 21.94 \\
Per capita household earnings & RSI & 14.49 & 18.43 \\
Average education of over-26s, by household & RSI & 21.69 & 26.02 \\
Households with head in high-status employment & Dissimilarity & $32 \%$ & $35 \%$ \\
Unemployment & Dissimilarity & $9 \%$ & $13 \%$ \\
Own-account without premises (non-professionals) & Dissimilarity & $13 \%$ & 10 \\
\hline
\end{tabular}

Source: Cervini and Gallo (2001), based on the Continuous Household Survey (ECH) carried out by the National Institute of Statistics (INE)

TABLE 2

Montevideo, groups of neighbourhoods: Incidence of poverty in the population and contribution to total poverty, indigence and population

\begin{tabular}{|c|c|c|c|c|c|c|c|c|}
\hline \multirow[t]{2}{*}{$\begin{array}{l}\text { Groups of } \\
\text { neighbourhoods }^{\text {a }}\end{array}$} & \multicolumn{2}{|c|}{$\begin{array}{l}\text { Incidence of poverty } \\
\text { in the population of } \\
\text { each neighbourhood }^{\mathrm{b}}\end{array}$} & \multicolumn{2}{|c|}{$\begin{array}{l}\text { Contribution of groups of } \\
\text { neighbourhoods to total } \\
\text { poverty in Montevideo }^{b}\end{array}$} & \multicolumn{2}{|c|}{$\begin{array}{l}\text { Contribution of groups of } \\
\text { neighbourhoods to total } \\
\text { indigence in Montevideo }^{b}\end{array}$} & \multicolumn{2}{|c|}{$\begin{array}{l}\text { Contribution of groups of } \\
\text { neighbourhoods to total } \\
\text { population in Montevideo }\end{array}$} \\
\hline & 1986-88 & $1995-97$ & $1986-88$ & $1995-97$ & 1986-88 & $1995-97$ & 1985 & 1996 \\
\hline Total & 34.5 & 15.8 & 100.0 & 100.0 & 100.0 & 100.0 & 100.0 & 100.0 \\
\hline 1 (No. = 3) & 66.7 & 45.0 & 9.4 & 14.2 & 14.1 & 21.4 & 4.8 & 6.5 \\
\hline 3 (No. $=14)$ & 45.7 & 20.4 & 30.5 & 30.8 & 30.4 & 25.9 & 23.2 & 23.6 \\
\hline $4($ No. $=15)$ & 29.1 & 9.7 & 20.2 & 13.2 & 14.4 & 7.9 & 22.3 & 20.6 \\
\hline 5 (No. $=7)$ & 23.1 & 6.7 & 6.8 & 4.5 & 3.7 & 2.8 & 10.4 & 9.8 \\
\hline 6 (No. $=6)$ & 14.7 & 4.0 & 5.3 & 3.1 & 3.2 & 3.9 & 12.8 & 11.7 \\
\hline 7 (No. $=3$ ) & 8.4 & 1.6 & 1.8 & 0.8 & 0.5 & 1.0 & 7.7 & 7.4 \\
\hline 8 (No. $=2)$ & 4.5 & 1.3 & 0.4 & 0.2 & 0.5 & 0.7 & 3.0 & 3.0 \\
\hline $\begin{array}{l}\text { Neighbourhoods } \\
\text { in groups } \\
1,2 \text { and } 3\end{array}$ & 52.5 & 27.2 & 65.5 & 78.2 & 77.7 & 83.7 & 43.9 & 47.5 \\
\hline
\end{tabular}

Source: Cervini and Gallo (2001), based on the INE Continuous Household Survey.

a Neighbourhoods grouped using the cluster multivariate method on the basis of household per capita income, the proportion of adults completing secondary education and the percentage of people with Ministry of Public Health medical coverage.

b Prepared by the authors using data from the INE Continuous Household Survey.

c Prepared by the authors using INE (1998) data.

TABLE 3

Montevideo: Neighbourhood structures in 1996, by population changes between the 1985 and 1996 censuses and average population density in each neighbourhood

Type of neighbourhood by population change between censuses (1985-1996)

\begin{tabular}{lrrr}
\hline Losing population & & 20.0 & 75.0 \\
Stable & 9.1 & 60.0 & 20.0 \\
Gaining population & 81.8 & 20.0 & 5.0 \\
Total & 100.0 & 100.0 & 29.0 \\
Total neighbourhoods & 22 & 20 & 100.0 \\
\end{tabular}

Source: Prepared by the authors using INE (1998) data.

a Rates of change between 1985 and 1996 censuses: neighbourhoods losing population, below $-4 \%$; stable neighbourhoods, between $-4 \%$ and $+3 \%$; neighbourhoods gaining population, over $+3 \%$. Gross population density in 1996 : density is considered low up to 6,000 inhabs./ $\mathrm{km}^{2}$, medium from 6,000 to 10,000 inhabs. $/ \mathrm{km}^{2}$ and high over 10,000 inhabs. $/ \mathrm{km}^{2}$. 
TABLE 4

Montevideo: Percentage breakdown of neighbourhoods by population changes between censuses, ${ }^{a}$ social composition and risk situations index, 1996

\begin{tabular}{lcccc}
\hline Neighbourhoods & $\begin{array}{c}\text { Losing } \\
\text { population }\end{array}$ & Stable & $\begin{array}{c}\text { Gaining } \\
\text { population }\end{array}$ & Total \\
\hline
\end{tabular}

Social composition

of neighbourhood

$\begin{array}{lrrrr}\text { Low } & 4.8 & 22.2 & 69.6 & 33.9 \\ \text { Medium } & 38.1 & 38.9 & 21.7 & 32.3 \\ \text { High } & 57.1 & 38.9 & 8.7 & 33.9 \\ \text { Total } & 100.0 & 100.0 & 100.0 & 100.0\end{array}$

Social risk index

of neighbourhood

57.1

33.3

38.9

4.3

32.3

Medium

High

Total

9.5

44.4

16.7

100.0

100.0

26.1

69.6

33.9

No.

21

18

23

100.0

62

Source: Prepared by the authors on the basis of Kaztman (1999), using data from the seventh General Population Census (INE, 1998).

a Rates of change between the 1985 and 1996 censuses are used to distinguish between neighbourhoods that are losing population (below $-4 \%$ ), stable (between $-4 \%$ and $+3 \%$ ) and gaining population (over $+3 \%$ ). The social composition of neighbourhoods is measured using the percentage of high-status occupations (professionals, managers, technical workers, etc.), and the risk index is calculated as the standardized sum of risk indicators (teenage motherhood, educational deficiency and young people not studying, working or seeking work).

whose ability to absorb labour, stimulated by import substitution and the expansion of the State apparatus, kept open important avenues of social mobility.

The little information available about the formation of poor neighbourhoods since the 1980s yields a different picture. First, the population concerned has mainly been urban in origin, moving from other parts of the city of Montevideo itself. ${ }^{4}$ In other words, if the formation of marginal settlements in the mid-twentieth century was driven by the strong pull of cities, since the 1980s it is mainly expulsion processes that have been at work. Secondly, if what characterized the situation confronting the urban poor in the 1950s was the widening of channels of mobility, the most prominent feature of today's situation is the narrowing of those channels. Thirdly, the increasing

\footnotetext{
${ }^{4}$ Even in 1984 most residents of these settlements (93.5\%) had been born in urban areas, three quarters of them in Montevideo itself (Cecilio, 1996).
}

territorial concentration of the poor has been paralleled by the movement of the upper-middle and upper classes to exclusive neighbourhoods, some of which have adopted the gated community model (Álvarez, 2004). As the same author stresses, however, the phenomenon of exclusive neighbourhoods is far smaller in scale in Montevideo than in other large cities of the Southern Cone, such as São Paulo (Caldeira, 2000) and Buenos Aires (Svampa, 2002). In fact, according to Álvarez, in 2003 there were only 10 gated communities in Greater Montevideo, housing 315 families..$^{5}$ In other words, without seeking to deny the contribution of the new exclusive neighbourhoods to the recent tendency towards urban fragmentation, it can be said that this contribution has been much slighter in Montevideo than in other South American cities. Lastly, the heterogeneity that still exists in some lower or lower-middle class neighbourhoods has been affected by the departure of better-off families seeking to avoid the risks associated with rising tensions and insecurity in these areas. ${ }^{6}$ All these movements have contributed to the fragmentation of the urban social fabric as a whole.

In sum, the processes currently giving rise to the spatial concentration of poverty in Montevideo are more likely than those of the past to generate situations of isolation between classes and of vulnerability to social exclusion.

\section{Why has the social composition of poor neighbourhoods in Montevideo become more homogeneous?}

Historically, many cities that have experienced significant spatial concentration of poverty have previously displayed considerable increases in urban density and in the social mobility of their populations. These two processes, accentuated by an expansion of transport and communications that facilitates the separation of the home and workplace, are usually associated with a widening of land price differentials between the different areas of the city, and with the development of a real-estate logic that distributes the

\footnotetext{
${ }^{5}$ As compared to 434 gated communities inhabited by 13,500 families in Greater Buenos Aires in 2000, according to Svampa (2002).

${ }^{6}$ Interviews carried out as part of a study examining the resources available to low-income urban families for dealing with critical situations (Zaffaroni, 1999) document cases where households have moved away from particular neighbourhoods to "flee" what they perceive as grave conditions of insecurity.
} 
population around the urban space in accordance with income.

Despite the evidence of a significant rise in the spatial concentration of the poor, Montevideo has not displayed either of these characteristics. When developments there since the mid-twentieth century are compared with those in other cities of the region, it is striking how little its population has grown. Nonetheless, a number of studies — Lombardi (1989), Retamoso (1999), Kaztman, Corbo and others (2003) - have shown that beneath the apparent calm of the city's demographic dynamic there have been massive population movements, particularly in the last 20 years, most of them from the centre of the city to its outskirts. ${ }^{7}$ Again, there is no evidence for significant upward social mobility. What little information is available on this seems rather to indicate an alternation between periods of immobility in the social structure and periods of downward mobility for large segments of the middle classes.

In the view of the authors, the likeliest explanation for the increased spatial concentration of the poor in Montevideo involves at least three factors: insufficient demand for low-skilled labour, liberalization of the rental market, and the retrenchment of public housing policies at a time when social spending is increasingly absorbed by pension payments. ${ }^{8}$ The combination of

\footnotetext{
7 "In the midst of this polarization there are, however, countercurrents in the location of the most vulnerable households. The empirical studies by Mazzei and Veiga (1985a, 1985b and 1986) in the mid-1980s found that some informal settlements were not distributed in rings around the city but tended to be enclaves close to the places where work was available. These enclaves are either located close to rich neighbourhoods, or use poor-quality housing in city centre areas (Portes, 1989). The determining factor that these two types of residential location have in common is their proximity to places where work is created. However, the survival of location patterns oriented by service-related work opportunities is threatened by a property development logic which, driven by changes in urban land prices, is tending to displace the poorest from higher-density areas and from the vicinity of residential areas" (Kaztman, 1999).

${ }^{8}$ The general attitude of the political system towards land occupation must also be regarded as one of the factors giving rise to the rapid growth of irregular settlements in Montevideo.
}

these forces has driven many families to seek solutions for their housing problems on the cheapest urban land, or simply to occupy land and build makeshift dwellings on it.

Concerning the demand for low-skilled labour, it can be argued that general constraints on labour absorption capacity are nothing new in Uruguay. Even by the closing stages of the import substitution period, what was termed the "dynamic insufficiency of the economy" was something to which specialists in these subjects were pointing with concern. Thus, the new feature introduced by the recent widening of the country's competitiveness frontiers and the rapid shift towards technology use has been a worsening both of dynamic insufficiencies already existing in the market and of the gap between the employment situations of the skilled and unskilled.

In these circumstances, the deregulation of rents has placed a growing proportion of the unskilled in a situation where they are unable to pay their rent or find people prepared to stand surety for their letting contracts, which in any case are not certain to be honoured. As early as 1994, a study warned that irregular settlements were expanding strongly and that a significant proportion of their inhabitants came from "houses or apartments", which led the authors to surmise that land occupation came to be seen as an option when it proved impossible to carry on living in homes in the "formal" market, a situation that appeared to be particularly prevalent in the case of young, recently formed households (Cecilio, 1996).

In sum, given existing housing policies, different ground rents and the forms taken by real-estate speculation, the processes referred to have produced a progressive shift of poor families to the cheapest neighbourhoods in the city or, in the case of settlements, to cost-free land occupation. In relation to this, the literature on the subject in Uruguay is united in asserting that the most important single factor behind the current level of residential segregation in Montevideo has been the pauperization and occupational instability affecting a large number of wage earners. 


\section{III}

\section{Employment trends}

As in other cities, the new poverty in Montevideo largely derives from what is now regarded as one of the dominant features of modern labour markets, the weakness of their attachments with the low-skilled. During the import substitution period, these attachments were solid enough for a significant proportion of workers, particularly those who entered what were then emerging industries, to be able to plan their lives, construct their identities and build reasonable expectations of social mobility around their work. ${ }^{9}$

These prospects and plans are usually unviable now. Some figures encapsulate the changes in the labour market that support this statement. Between 1970 and 1999, the State almost halved (from 28\% to $16 \%)$ its presence in that market. Something similar happened with industry, which employed $32 \%$ of the workforce in 1970 but only $16 \%$ in 2002 . At the same time, the female economically active population (EAP) greatly increased, raising its participation rate from $27.5 \%$ to $52.5 \%$ over those 30 years in a context of poor job creation, thus contributing to higher unemployment, poorer working conditions and lower wages. Beginning in 1980, well-capitalized businesses came to the fore in trade and services, displacing significant numbers of semi-formal small business owners who had been the backbone of a substantial self-employed middle class. From the second half of the 1990s onward, there was also a rise in the number of recurrent short-term crises.

The processes summarized here led to higher joblessness and increasingly to the unstable, substandard and unproductive employment that characterizes the informal sector, the result being an ever-widening gap between less and more highly skilled workers (Kaztman, Corbo and others, 2003; UNDP, 2001). ${ }^{10}$

These characteristics of employment are the single most important factor not only behind the persistence of poverty in the current generation, but also behind the reinforcement of the mechanisms that reproduce it between generations. This is because adults who do not have the capabilities and skills needed to stay clear of unstable, substandard employment will hardly be in a position to transfer to their children the physical, human and social capital these will need to develop fully in post-industrial societies.

Given their strong impact on the characteristics of the urban poor, it is worth looking a little more closely at industrial developments in Montevideo. The city has not only shared in the general decline of industry across the country, but has been losing its supremacy. Whereas in 1960 it was responsible for $78 \%$ of gross industrial output, by the early 1990s the figure was 60\% (Becker, Jager and Raza, 2001). This twofold process - general industrial decline and the loss of supremacy - has severely affected the employment capacity of factories that, sited in different areas of the capital, used to recruit mainly in their immediate neighbourhoods. This pattern of recruitment favoured the formation of dense networks of relationships between families, local residents and work colleagues. ${ }^{11}$ With the decline of the import substitution model, many industries closed their doors, stable jobs like those in the public sector became scarcer and Montevideo lost some of its former industrial supremacy.

\footnotetext{
${ }^{9}$ Much of the social integration that used to be the rule in Uruguay was based on the nature of the so-called import substitution model, which was the result of an alliance extending to about $80 \%$ of the population and resting on an anti-Schumpeterian triangle between the State, the protected industrial bourgeoisie and their workers.

${ }^{10}$ It could be retorted that the employment crisis, and the resultant increase in uncertainty as regards well-being, have affected all social
}

strata. It is unquestionably true, though, that those who have accrued more human capital are better placed than the rest to take advantage of the opportunities offered by a production structure that is increasingly knowledge-based and is incorporating technological innovations with greater and greater rapidity.

${ }^{11}$ The stability of factory employment also encouraged workers to set up home near their workplaces. 


\section{IV}

\section{Residential and occupational segregation}

In any attempt to identify relationships between contextual characteristics (segregated neighbourhoods) and individual ones (employment situation, poor working conditions) it is advisable to keep a critical eye on the direction of causality, without losing sight of the possibility of movement in the opposite direction, where the supposed causes are affected by the supposed consequences. In the case of the relationships between a person's employment situation and the location of his or her home, the line of causality most often examined is that posited by the assumption that those with the greatest problems in the labour market are most likely to take up residence in the poorest neighbourhoods. Because this association is so reasonable, it cannot be surprising if the concentration of low-skilled populations in certain neighbourhoods is usually interpreted rather as a consequence than as a cause of what happens to people in the labour market.

The evidence provided by studies looking at the rapid growth of irregular settlements on the outskirts of the city of Montevideo backs up this interpretation. These studies report that the inability to pay rents, find surety for letting contracts or, in some cases, pay the taxes on small properties are the most important single reasons for the mass displacement of young families from relatively central areas of the city to more outlying ones. This displacement, which increases the territorial concentration of poverty, is compounded by rising homogenization in the social composition of outlying neighbourhoods due to the growing employment difficulties faced by established residents of these areas.

But even admitting that employment opportunities are a major cause both of displacements towards neighbourhoods where the poor are concentrated and of the "new" impoverishment of their existing residents, it must also be recognized that, once people are established or remain in these areas of more concentrated and homogeneous poverty, any attachments they have to the labour market will be affected by factors and processes characteristic of surroundings where there is a high density of need. The effects of the context of residence will show themselves more clearly in the generations that are socialized in these areas, for whom the neighbourhood influence clearly precedes their efforts to enter the labour market.

The tables that follow show the distribution of certain substantive indicators of instability (the unemployment rate), informal working (own-account work) and substandard working conditions (lack of health coverage) affecting residents of different census blocks in Montevideo in accordance with their social composition. Given that the census does not ask about household income, the operational definition of the social composition of census blocks was based on the average educational level of the households living in them. ${ }^{12}$ The data are from the 1996 population and housing census, and thus cover the entire economically active population of the city.

Table 5 shows the unemployment rate, used in this case as a proxy variable for instability of employment, for the Montevideo census blocks classified into three categories by the percentage of low-education households. The information is broken down by residents' age, sex and years of education.

The table shows that the behaviour of unemployment has a systematic inverse relationship with the average education levels used to characterize the social composition of census blocks, and that this holds true irrespective of the sex, age and education of individuals. ${ }^{13}$

Similar considerations arise from tables 6 and 7. The purpose of these is to estimate the distribution between neighbourhoods of informal activity (using own-account working as a proxy) and of substandard working conditions (the lack of legally mandated health protection). Controlling by individuals' education level offers a way, albeit an imperfect one, of testing the causal effect that context may have on individuals. Regardless of how they are ultimately interpreted,

\footnotetext{
12 This indicator was constructed in two stages. In the first, a calculation was made for each census block of the percentage of households with a low educational level, this classification being applied to households where the average number of years' schooling of members aged over 18 did not exceed the equivalent of incomplete primary education (less than six years of education). In the second stage, once the city's 1,032 census blocks had been ranked by the percentage of households with a low level of education, the distribution was divided into deciles. The deciles were then grouped into three categories. The "low education context" includes the $30 \%$ of deciles with the highest percentage of low-education households, the "medium education context" covers the four intermediate deciles, and the "high education context" covers the $30 \%$ of deciles with the fewest low-education households.

${ }^{13}$ Note that the intervals between the years of individual education are small enough to minimize the possibility of the dependent variable being affected by variations within each interval.
} 
Montevideo: Unemployment rate by educational context of census block and by residents' age, sex and education, 1996

\begin{tabular}{|c|c|c|c|c|c|c|c|c|c|c|}
\hline \multirow{2}{*}{\multicolumn{2}{|c|}{$\begin{array}{l}\text { Age and } \\
\text { education }\end{array}$}} & \multicolumn{9}{|c|}{ Educational context of census block } \\
\hline & & \multicolumn{3}{|c|}{ Low } & \multicolumn{3}{|c|}{ Medium } & \multicolumn{3}{|c|}{ High } \\
\hline Age & Education & Male & Female & Total & Male & Female & Total & Male & Female & Total \\
\hline \multirow{7}{*}{15 to 29} & Incomplete primary & 22.8 & 39.0 & 27.0 & 22.2 & 33.4 & 25.6 & 17.6 & 24.1 & 19.7 \\
\hline & Complete primary & 21.6 & 33.7 & 25.3 & 23.5 & 32.3 & 26.2 & 19.1 & 26.9 & 21.6 \\
\hline & 7 and 8 years & 19.6 & 29.9 & 23.5 & 20.2 & 26.6 & 22.7 & 17.5 & 21.5 & 19.0 \\
\hline & 9 and 10 years & 17.2 & 24.3 & 20.3 & 16.0 & 22.6 & 19.0 & 15.2 & 19.4 & 17.1 \\
\hline & 11 years & 15.6 & 20.9 & 18.2 & 13.4 & 20.5 & 16.8 & 13.8 & 17.3 & 15.5 \\
\hline & 12 years plus & 12.9 & 16.3 & 14.8 & 13.6 & 15.6 & 14.8 & 12.7 & 16.1 & 14.6 \\
\hline & Total & 19.6 & 27.7 & 22.7 & 18.1 & 22.4 & 20.0 & 14.7 & 17.8 & 16.2 \\
\hline \multirow{7}{*}{30 plus } & Incomplete primary & 13.0 & 16.0 & 14.1 & 10.6 & 13.6 & 11.8 & 7.5 & 9.8 & 8.5 \\
\hline & Complete primary & 11.2 & 16.9 & 13.4 & 10.1 & 14.3 & 11.8 & 7.2 & 10.0 & 8.4 \\
\hline & 7 and 8 years & 11.0 & 16.0 & 13.1 & 9.2 & 14.3 & 11.4 & 6.4 & 10.1 & 8.0 \\
\hline & 9 and 10 years & 8.5 & 14.0 & 10.9 & 7.1 & 11.3 & 9.0 & 5.1 & 8.8 & 6.8 \\
\hline & 11 years & 8.6 & 11.9 & 10.1 & 6.2 & 9.0 & 7.6 & 4.8 & 7.0 & 6.0 \\
\hline & 12 years plus & 7.2 & 8.4 & 7.7 & 4.6 & 5.2 & 4.9 & 2.4 & 4.2 & 3.3 \\
\hline & Total & 10.7 & 15.0 & 12.4 & 8.0 & 10.8 & 9.3 & 4.3 & 6.6 & 5.4 \\
\hline \multirow{7}{*}{ Total } & Incomplete primary & 15.1 & 19.4 & 16.5 & 12.0 & 15.1 & 13.2 & 8.2 & 10.5 & 9.2 \\
\hline & Complete primary & 15.0 & 21.9 & 17.5 & 13.7 & 17.6 & 15.2 & 9.7 & 12.3 & 10.8 \\
\hline & 7 and 8 years & 15.2 & 22.4 & 18.0 & 14.0 & 19.1 & 16.0 & 10.8 & 13.7 & 11.9 \\
\hline & 9 and 10 years & 11.9 & 18.2 & 14.7 & 10.1 & 15.1 & 12.4 & 8.3 & 12.1 & 10.0 \\
\hline & 11 years & 11.5 & 16.0 & 13.6 & 8.7 & 12.9 & 10.8 & 7.7 & 9.9 & 8.8 \\
\hline & 12 years plus & 9.0 & 11.5 & 10.2 & 7.1 & 8.6 & 7.9 & 5.1 & 7.9 & 6.5 \\
\hline & Total & 14.0 & 19.4 & 16.1 & 11.1 & 14.3 & 12.5 & 7.2 & 9.8 & 8.5 \\
\hline
\end{tabular}

Source: Prepared by the authors using unpublished data from the Activos y estructura de oportunidades project (Kaztman, 1999).

however, the results raise questions like the following: what are the mechanisms that operate so that, for example, people who have completed 11 years of schooling (the only one of the education categories in the table to cover just a single year), whether they are younger or older (and, in the case of unemployment, whether they are men or women), and who live in neighbourhoods whose social composition indicates a high concentration of need, display higher rates of unemployment, higher percentages of own-account working and lower health coverage than people with the same level of schooling who live in different neighbourhoods?

As has just been said, the explanation for these associations is not simple, particularly where the direction of causality is concerned. On the one hand it can be argued that, irrespective of the level of education they have attained, people who are more likely to be unemployed will tend to congregate in the poorest neighbourhoods. The empirical patterns observed will then be interpreted as a selection process implicit in the relationship between the poverty of the neighbourhood and its residents' attachments to the labour market. According to this view, the most disadvantaged neighbourhoods are the receptacle for the "losers" of the system, those who for one reason or another do not manage to establish a stable, protected and remunerative link with the world of work and who, not having the resources to meet the costs of living in other parts of the city, are forced to move with their families to marginal areas. If this is so, the differences found between the residents of different neighbourhoods should be attributed not to the influence of contexts that socialize or limit opportunities in a differentiated way for those living in them, but simply to the territorial aggregation of those who share experiences of failure in the world of work.

On the other hand, the opposite argument can be made, i.e., that the direction of causality runs from the characteristics of the neighbourhood to its residents' employment situation. Here, it is worth bringing in some empirical information that can show the way to a more accurate interpretation of the relative importance of the two possible lines of causality linking territory and employment. The data in table 8 are given with this end in view. 
TABLE 6

Montevideo: Percentage of own-account workers, by educational context of worker's census block and worker's years of education, ${ }^{\text {a }} 1996$

\begin{tabular}{lrrrr}
\hline \multirow{2}{*}{$\begin{array}{l}\text { Worker's } \\
\text { education }\end{array}$} & \multicolumn{4}{c}{ Educational context of census block } \\
\cline { 2 - 5 } & Low & Medium & High & Total \\
\hline Less than 6 years & 24.8 & 23.4 & 20.5 & 23.8 \\
6 years & 18.9 & 18.0 & 16.9 & 18.3 \\
7 and 8 years & 15.5 & 14.6 & 12.8 & 14.6 \\
9 and 10 years & 13.5 & 11.7 & 8.9 & 11.2 \\
11 years & 10.8 & 8.6 & 6.5 & 8.0 \\
12 years or more & 8.5 & 5.1 & 3.0 & 4.1 \\
Total & 17.0 & 12.6 & 7.1 & 11.9 \\
\hline
\end{tabular}

Source: Prepared by the authors using unpublished data from the Activos y estructura de oportunidades project (Kaztman, 1999).

a Excludes managers, professionals and technical workers.

TABLE 7

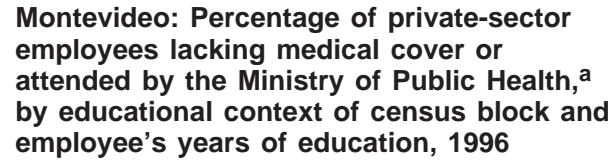

\begin{tabular}{lrrrr}
\hline \multirow{2}{*}{$\begin{array}{l}\text { Worker's } \\
\text { education }\end{array}$} & \multicolumn{4}{c}{ Educational context of census block } \\
\cline { 2 - 5 } & Low & Medium & High & Total \\
\hline Less than 6 years & 37.5 & 25.4 & 18.3 & 31.0 \\
6 years & 34.6 & 23.7 & 18.0 & 28.1 \\
7 and 8 years & 27.5 & 19.1 & 14.3 & 21.2 \\
9 and 10 years & 18.8 & 11.1 & 7.5 & 11.9 \\
11 years & 13.4 & 7.9 & 4.9 & 7.6 \\
12 years or more & 11.3 & 5.7 & 3.6 & 5.0 \\
Total & 27.6 & 14.7 & 7.4 & 16.2 \\
\hline
\end{tabular}

Source: Prepared by the authors using unpublished data from the Activos y estructura de oportunidades project (Kaztman, 1999).

a Under current legislation, private-sector employees acquire the right to medical care in group medical assistance institutions (IAMC). For employees not to receive such care and to be lacking in medical coverage or attended by the Ministry of Public Health (MSP) suggests they may not be registered in the social security system.

The table shows the situation of young people aged 15 to 19 who are still living in their households of origin and are unaffiliated with institutions like workplaces and educational establishments, crucial to the transition to the adult world. These are young people who are not working, studying or seeking work. For our purposes, what is interesting about this indicator is that the ages of the people concerned make it reasonable to assume that they include a large proportion of adolescents and young people who were born or have been socialized in the neighbourhoods
TABLE 8

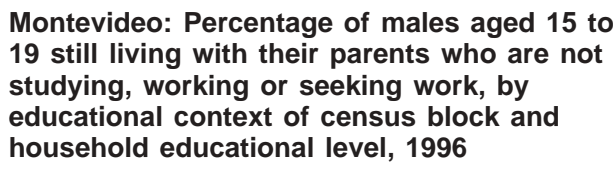

\begin{tabular}{lcccc}
\hline $\begin{array}{l}\text { Educational level } \\
\text { of household }\end{array}$ & \multicolumn{4}{c}{ Educational context of census block } \\
\cline { 2 - 5 } & Low & Medium & High & Total \\
\hline Up to 6 years & 28.2 & 24.9 & 19.1 & 26.3 \\
Over 6 and up to 9 & 26.2 & 23.3 & 16.1 & 23.1 \\
Over 9 & 21.9 & 18.1 & 12.5 & 15.5 \\
Total & 26.8 & 22.0 & 13.8 & 21.4 \\
\hline
\end{tabular}

Source: Prepared by the authors using unpublished data from the Activos y estructura de oportunidades project (Kaztman, 1999).

where they live, and that it was not they themselves who decided to take up residence in those areas. Thus, if it could be shown that these age groups displayed patterns similar to those described above, the line of causality whereby the characteristics of the place of residence are attributed to the problems of labour market participation would look weaker. The table takes account of the parents' educational level, given that this variable has proved to be one of the most powerful predictors of institutional disaffiliation among adolescents and young people (ECLAC, 1997; MEMFOD, 2002).

As in the previous cases, the results show a statistically significant negative relationship between the average socio-economic level of the neighbourhood where young people live and the incidence of institutional disaffiliation, regardless of the parents' educational level. Consideration should also be given here, however, to the possibility that the same configuration of resources as led to the parents taking up residence in poor neighbourhoods might have affected the children through family socialization. If this were the case, we would once again be faced with a spurious relationship between environment and behaviour, with the difference that on this occasion the family would be the intervening factor. This argument is lent credence by the fact that the educational level of parents actually does influence the institutional disaffiliation of their children. On the other hand, it is contradicted by the fact that, when the differences explained by one and the other variable are compared, it transpires that the social composition of the neighbourhood appears to have a greater effect than the educational level of the family in explaining the variations in the disaffiliation of young people.

With this empirical background, we can now turn to the mechanisms that might be activated in 
neighbourhoods with a high concentration of poverty and that could be affecting the type of attachments established by their residents with the labour market.

\section{Which are the factors associated with the so- cial composition of neighbourhoods that might be impeding the access of residents to the labour market?}

Before analysing the different mechanisms associated with living conditions in neighbourhoods with a high concentration of poverty (which will be helpful in exploring their effects on employment), brief consideration should be given to a basic question that arises when we seek to explain people's behaviour by the characteristics of the neighbourhoods they live in: which are the factors that determine whether people are more or less susceptible to the influences of the social environment in the place where they live? An initial approach to answering this is to separate the conditions deriving from global and analytical characteristics of the neighbourhood from those deriving from the characteristics of individuals living there.

Concerning the former, neighbourhoods have all sorts of attributes that are likely to affect residents. The most general one is physical proximity. When compared to other social networks that could operate as sources of recognition, sociability and identity formation - such as those constructed in the workplace, educational institutions and the associations and institutions in which residents participate- what characterizes the social network of the neighbourhood is that it is the one closest to people's private lives. Saraví (2004) exemplifies this very well when he says that "the neighbourhood [is] the first public encounter upon emerging from the private space".

While physical proximity makes it easier for the neighbourhood social network to influence people, the direction of this influence will vary depending on other characteristics. The following seem to be the most significant. First, the level of security and the general tone of the neighbourhood are important. With respect to the effects of these on the formation of residents' attitudes and expectations, Saraví (2004) says that "...the prevailing climate —of security or insecurity, violence or friendliness, mutual recognition or indifference- will mould the characteristics of the interactions and relationships that are constructed in local public spaces". A second significant factor is the social status of the neighbourhood. City dwellers usually have a clear image of where their neighbourhood stands in the general ranking of prestige among the different parts of the city. While the residents of some areas may be more sensitive than others to criteria such as the level of social disorder, the most general standard for this ranking is the average socio-economic level of the households living there. For the inhabitants of a neighbourhood, this image will weigh more or less heavily in the decisions they make about where to live, their openness to the influences of their immediate social environment and the importance they assign to their association with the neighbourhood in shaping their identities, depending on how much scope they have for choice. A third factor that helps explain the influence of a neighbourhood on the habits, behaviour and expectations of residents is its socioinstitutional fabric. The denser this fabric is, the more likely it will be that local standards will have a real influence in regulating the behaviour of residents.

As for individual characteristics, the differences in people's receptiveness to the influences of their neighbourhood environment will depend, among other factors, on their "free valencies". The narrower the spheres available to them for satisfying their need for recognition, identity and belonging, the more susceptible they will be to the influences of the neighbourhood social fabric and the readier to change or adopt habits and expectations as a result of interactions with other residents. This being so, neighbourhood influences on behaviour might be expected to be greater among those sectors of the urban population that are most vulnerable to social exclusion, precisely because the process of exclusion entails a progressive reduction of other sources of belonging, recognition and identity outside the neighbourhood.

These brief observations on some of the aspects that might help determine the influence of local surroundings on behaviour call into question any supposition that neighbourhoods may have a uniform impact on individuals. A great number of case studies are still needed to create and hone the conceptual frameworks which will help us to understand differentials in the susceptibility of residents to their neighbourhoods. With these caveats, we shall now proceed to analyse the mechanisms involved.

\section{Mechanisms that mediate between neighbourhood contexts and individual behaviour}

There are a number of mechanisms, some of which have already been extensively examined in the specialist literature, that mediate between aspects of a 
neighbourhood and the behaviour of its residents. Although the mechanisms discussed below do not coincide with those identified by Small and Newman (2001), in presenting them we shall use the distinction drawn by those authors between instrumental mechanisms and socialization mechanisms.

\section{a) Instrumental mechanisms}

Instrumental mechanisms are the different channels through which neighbourhood conditions can constrain individual action. In this category we include the following: distance to workplaces and the costs in time and money associated with transport, local employment opportunities, the scope for accumulating social capital that is useful for finding work, the difficulty of mobilizing the family workforce because of insecure surroundings, and the reaction of potential employers to the idea of recruiting residents of these neighbourhoods.

If concentrations of poor households arise in neighbourhoods on the outskirts of cities, the extent to which transport is a problem for residents will depend on how much it costs as a proportion of their income. Case studies dealing with poor young people in Montevideo have found that these costs, as well as placing severe constraints on job-seeking, heavily influence people's decisions as to whether or not to accept jobs that are very poorly paid once the cost of travel has been deducted. It must be remembered here that the pronounced shift towards personal services in urban demand for unskilled workers has mainly occurred in those neighbourhoods where the most wellto-do population lives, and which have the highest property values and rentals in the city. Because the low-skilled therefore have difficulty in finding places to live near their potential workplace, transport costs and journey times affect their employment prospects. ${ }^{14}$ In fact, it is possible to find pockets of poverty around the upper-middle and upper class areas of Montevideo, undoubtedly as the result of elaborate strategies by lower-income households to match their housing to their work.

A second mechanism, whose impact varies with the concentration of poverty in a neighbourhood, is provided by small industrial or repair workshops and

\footnotetext{
${ }^{14}$ Suárez (2004). According to this author, "many of those interviewed said that they stuck to doing odd jobs in their own neighbourhood or nearby, because 'it costs money to go out looking for work'; 'you can't pay the bus fare every day to go after work' ...".
}

businesses offering services of various kinds. In poor neighbourhoods where a relatively high proportion of workers had stable jobs, adolescents and youths used to benefit from the presence of these enterprises, which offered a major resource for obtaining their first work experience as assistants, apprentices or helpers in different tasks. It should be noted that, in these cases, the realization that there were potentially gainful work opportunities in the neighbourhood gave families a further reason to invest in building up local social capital, as they could realistically expect this capital to materialize in the form of actual jobs.

One consequence of the loss of industrial dynamism, the liberalization of imports of cheap household electrical goods of all kinds and the growing presence of large investors in the supermarket business was the gradual disappearance of many of these small businesses and workshops. What can now be seen, both in the old working-class areas and in the neighbourhoods that are forming on the outskirts of the city, are, firstly, individuals selling all kinds of second-hand items or home-made foodstuffs, a trade that is often concentrated in markets situated at different points around these neighbourhoods, and secondly, family microenterprises with minimal infrastructure that operate inside homes or as extensions to these. In these circumstances, only a few businesses are formal and dynamic enough to need more labour than can be mobilized within the home in the form of unpaid family workers.

Concerning the prospects of obtaining a return on social capital by finding work, the increase in spatial segregation has had another negative consequence. This is because construction of the other type of social capital - “weak links", in Granovetter's (1985) terminologythat the poor usually rely on as a vital source of useful information and contacts in their efforts to enter the world of work is being increasingly obstructed by the growing physical separation from other social classes and the narrowing of the spheres of interaction with them that this segregation has entailed. ${ }^{15}$

\footnotetext{
${ }^{15}$ During the period when public-sector employment was expanding, there were networks of social capital based on political patronage that penetrated deeply into the poor neighbourhoods of Montevideo, expanding their residents' opportunities for finding work. As their room for manoeuvre was diminished by the growing pressure to put the fiscal accounts in order, the politicians who operated these networks were gradually deprived of the resources they needed to sustain them. See Rama (1971) and Luna (2004) for an analysis of the processes seen when political patronage flourished in Uruguay and again when it went into decline (or changed its nature).
} 
The constraints that public insecurity places on the ability of the workforce to travel from home are a fourth instrumental mechanism. Fear of assault, robbery and the exposure of children to unwanted influences paralyses household resources that could be used to generate income and moulds survival strategies. The effects of a climate of insecurity can be seen in people's choice of occupations, the constraints on the times at which they will travel through public spaces that residents have ceased to control, and the need to allocate human resources from the family to looking after household property or children who cannot be left alone and have to be accompanied to their places of study or recreation.

Lastly, the increased physical and social distance between the populations of poor neighbourhoods and the rest of the city also alters the way the social classes regard one another. These alterations result from a combination of two processes. Firstly, as the opportunities for social interaction between the classes diminish, those classes that are part of the mainstream of urban society gradually lose their ability to "put themselves in the other's place" (empathy). This tends to raise their tolerance threshold for both inequality and the various manifestations of wretchedness on the streets of the city. Secondly, the high density of need in poor neighbourhoods creates fractures in their social fabric through which marginal subcultures can germinate. The resultant disorder affects the public image of these neighbourhoods. Those where patterns of behaviour are perceived by the rest of urban society as being more exotic and dangerous are written off as "no-go areas". The combination of the two processes helps to create stigmas. These stereotyped images can come to count for a great deal in the collective identification of those who, exposed to similar experiences of discrimination, gradually discover a painful community of problems and destinies with their neighbours. What is important for our purposes is that these images, which place a negative stamp on certain areas of the city, also colour the judgement of employers when they recruit unskilled labour. In turn, the realization that inhabitants of these areas are rejected as potential candidates for employment because of where they live leads many young jobseekers to conceal their place of residence.

\section{b) Socialization mechanisms}

These mechanisms, which include things like the existence of role models in the neighbourhood, the efficiency of community standards and the presence of marginal subcultures, are closely interrelated. Where labour market attachments are concerned, the most important consequence of their operation is the degree to which people are exposed to signals, images and habits that justify and reinforce discouragement, cast doubt over the prospects of escaping from poverty through work, or call into question mental content consistent with the formation of a culture of work.

A first factor here is the absence in the immediate social environment of role models who can convey the work-related expectations, habits and types of behaviour that predominate in the social and economic mainstream of the city. Such models are living proof that it is possible to escape from poverty and improve family welfare by making use of the opportunities available within the legal framework that regulates the world of work. ${ }^{16}$ Regular contact with such people can help raise expectations of future well-being, encourage discipline and a work ethic and, in particular, strengthen the conviction that continuing investments in education and training will eventually be rewarded by significant achievements. Of course, there are so many instances of downward mobility in the poor neighbourhoods of Montevideo that the conditions are not favourable for contacts of this type.

Two other, closely interrelated factors militate against the formation of a culture of work. One is the inefficiency of the standards governing relations among residents, a key aspect of community social capital. The pressures placed on households by the needs of dayto-day survival, and the dearth and instability of the bare resources needed to sustain reciprocity networks or community-based institutions, conspire against the generation and maintenance of general patterns of community life. The other factor, which tends to arise as a corollary, is the presence of marginal subcultures. Neighbourhoods with high concentrations of poverty experience a latent but perpetual struggle between the two options. There are those who try to resist social disaffiliation and those, already discouraged, who are willing to break with normal standards and explore non-legitimate ways of improving their living conditions. By lending support to those who take this route, marginal subcultures make work less attractive as a means of achieving welfare goals.

\footnotetext{
16 The "role model" function can also be fulfilled by residents who achieve economic success illegally, something that is common in neighbourhoods where there is organized criminal activity such as drug dealing and the selling of parts from stolen and dismantled cars, or semi-criminal activity such as small-scale merchandise smuggling.
} 


\section{Box}

The issue of the costs entailed for poor households by a climate of insecurity in their neighbourhoods has been largely neglected in the literature, so that it is worth giving a few examples of what it means in practice for those affected. A woman interviewed in a disadvantaged neighbourhood in Greater Buenos Aires, speaking of the occupation she works in, says (Suárez, 2004):

"Those are the kinds of work I can do... With children it's hard to do anything else. They need me at home... if you're not there, heaven knows what they'll get up to... Before I got married I worked in a hotel in Once, but now I can't be out all day."

Similar problems are brought up by people living in poor areas of Montevideo (Zaffaroni, 1999):

- "When I go to work I have to leave the little ones shut in all afternoon, I can't leave them here on their own. Kids go around on drugs. If we have to go out, I go or Julio goes, we can't go out together. If you leave the place empty, you won't even have any windows by the time you get back."

- "They give the children milk in the snack bar, but I can't let them go on their own, I'd rather do them their milk here."

- "Where we lived was one of the worst places. That's why we had to leave a house that was ready to live in and a working shop."

- "You can't leave your son on a street corner with other boys, because they'll be taking cocaine or sniffing glue there."

- A woman says that after a burglary: "We just stopped going out after that, and it's been almost two years. Unless we've got someone to mind the place. Otherwise we don't go out."

- "They're thieves. You can't go out for two hours without everything being stolen."

Source: Suárez (2004) and Zaffaroni (1999).

\section{V}

\section{Final considerations}

This article has aimed to set forth a range of reflections and empirical information concerning two processes that are affecting the characteristics of poverty in the city of Montevideo: the weakening of less-skilled workers' attachments to the urban labour market and the increasing concentration of these workers and their families in neighbourhoods with a high density of poverty. While far from conclusive, the results of this exercise suggest that it would be worth looking more thoroughly into the relationship between changes in the social morphology of the city on the one hand and the segmentation of its labour market on the other, considering the possibility of spurious findings, examining in detail the relative importance of each causal direction (from the context to the individual and from the individual to the context) and seeking to lay bare in all their complexity the mechanisms that operate between contexts and any effects they might have on individuals. As can be seen, this points the way to a whole research programme.

What is the justification for such a programme? The main argument for it is that, if the tendency towards an ever more polarized spatial distribution of the social classes in cities is confirmed, and if it can be shown that there are feedback mechanisms in the most disadvantaged neighbourhoods that compound the social isolation of their residents, then it will be safe to say that these are processes which, if not effectively counteracted, will lead ineluctably to the reproduction and amplification of what are already extremely marked inequalities in the large cities of the region. Any intervention strategy designed to foster integration 
on the basis of equity, the construction of citizenship and reinforcement of the social fabric will need to neutralize these processes, and will therefore need to have diagnoses available to it that can help towards an understanding of the nature of this perverse relationship between territory and work. ${ }^{17}$

It should be added that, to judge by the changes in the production structure of the city, any future recovery in labour absorption capacity will have a marked bias in favour of the best-skilled, and that differences in income and working conditions will continue to widen in their favour. The effects of socialization and instrumental mechanisms in the neighbourhoods where very needy households are increasingly concentrated can be expected to reinforce the tendencies referred to.

To simplify the exposition, this analysis has given a perhaps excessively linear and deterministic character to the factors driving social exclusion among the least skilled urban workers. In fact, the relative strength of the forces for exclusion and inclusion is determined by a whole range of possibilities. But the conflicts between these forces are present, openly or otherwise, in every neighbourhood. There are those who resist social disaffiliation and those who give themselves up to it, making do with a "second class citizenship". The argument of this essay is that, in Montevideo in recent years, the balance of this conflict has shifted towards the latter outcome.

Concerning work, this pessimistic view is supported by the conclusion that the residents of poor segregated neighbourhoods will only be able to capitalize on the opportunities created by any recovery if economic growth is much more vigorous than in the past. Indeed, there is no reason to think that sufficiently strong demand for labour cannot neutralize the mechanisms analysed, giving back hope to those who have lost it and, among those who never had much of it, making the attainment of decent living conditions by their own efforts seem a reasonable prospect. If this should happen, it seems reasonable to expect that in each segregated neighbourhood positive employment

\footnotetext{
${ }^{17}$ Similar explorations ought to be undertaken with regard to the mechanisms affecting access to services that are a source of assets in the form of physical, human and social capital, such as education, health care, housing infrastructure, public security, political activity and places of recreation, and that tend to be activated in tandem with the processes leading to the spatial segregation of the urban poor.
}

signals will gradually strengthen the position of those who are holding out against disaffiliation and weaken the arguments of the discouraged and disaffected.

The question, then, is rather how realistic a scenario of this kind is in the short and medium term. If the assessment sets out from current employment trends in the major cities of Latin America, it has to be said that these (other than in Mexico, which shares a border with the world's most dynamic labour market) still have relatively high unemployment rates, particularly among lower-skilled workers. As in Montevideo, this can be put down to weak and unstable economic growth and to the fact that this growth is heavily dependent for its dynamism on production activities of increasing technological density. In these circumstances, it is hard to see on what basis we can build expectations of major improvements in unemployment rates, in the indices of occupational instability and insecurity, and in the pay differences between skilled and unskilled workers, at least in the short and medium term. Accordingly, there is no reason to expect that mechanisms like those described will be neutralized either.

If attention is turned to the occupational opportunities for the coming generations, the fundamental problem is how to raise the qualification levels of children from poor homes and narrow the education gaps between the urban classes. A large number of studies have given indications of the effects on children's school performance of mechanisms similar to those discussed here in very needy neighbourhoods. The type of changes needed to neutralize these effects and give such children and adolescents hope for the future demand improvements in the coverage and quality of the educational system strong enough to enhance its ability to absorb and retain these young people, whose primary socialization takes place in such unsatisfactory surroundings.

As regards urban planning, there is a need for measures to reverse or check the process of residential segregation, keeping in mind that the economic and political costs of these measures rise exponentially as marginal subcultures crystallize. Consolidation of these subcultures usually takes place in parallel with the undermining both of the world of work as the core of urban adult identity formation, and of expectations of social advancement and real integration into the economic and social mainstream of society. Here as in other areas of social policy, prevention is the best cure. 


\section{Bibliography}

Álvarez, M.J. (2002): Asentamientos irregulares en Montevideo: la desafiliación resistida, working paper, Montevideo, Social Sciences Faculty, University of the Republic.

(2004): Moving to a Golden Ghetto, MA Thesis, Pittsburgh, Department of Sociology, University of Pittsburgh.

Amarante, V., R. Arim and A. Vigorito (2004): Pobreza, red de protección social y situación de la infancia en Uruguay, Washington, D.C., Inter-American Development Bank (IDB), draft.

Becker, J., J. Jager and W. Raza (2001): Economía política de Montevideo: desarrollo urbano y políticas locales, Montevideo, Centro Latinoamericano de Ecología Social (CLAES).

Caldeira, T. (2000): City of Walls: Crime, Segregation and Citizenship in Sao Paulo, California, University of California Press.

Cecilio, M. (1996): Relevamiento de asentamientos irregulares en Montevideo, Asentamientos irregulares, Montevideo, Ministry of Housing, Regional Planning and Environment.

Cervini, M. and M. Gallo (2001): Un análisis de exclusión social: la segregación residencial entre los barrios de Montevideo, 1986-1998, FCE thesis, Montevideo.

ECLAC (Economic Commission for Latin America and the Caribbean) (1997): Social Panorama of Latin America, 1996, LC/G.1946-P, Santiago, Chile. United Nations publication, Sales No. E.97.II.G.4.

Granovetter, M. (1985): Economic action, social structure and embeddedness, American Journal of Sociology, vol. 91, No. 3, Chicago, The University of Chicago Press.

INE (National Institute of Statistics) (1998): VII Censo General de Población, III de Hogares y V de Viviendas, Montevideo. (2002): Evolución de la pobreza por el método del ingreso, 1986-2001. Montevideo.

(2003): Estimaciones de pobreza por el método del ingreso. Año 2002, Montevideo.

(2004): Estimaciones de pobreza por el método del ingreso. Año 2003, Montevideo.

Jencks, Ch. and S. Mayer (1990): The social consequences of growing up in a poor neighborhood, in L. Lynn and M. McGeary (eds.), Inner City Poverty in the United States, Washington, D.C., National Academy Press.

Kaztman, R. (coord.) (1999): Activos y estructura de oportunidades: estudio sobre las raíces de la vulnerabilidad social en Uruguay, LC/MVD/R.180, Montevideo, ECLAC office in Montevideo.

Kaztman, R., G. Corbo and others (2003): La ciudad fragmentada: respuesta de los sectores populares urbanos a las transformaciones del mercado y del territorio en Montevideo, Working Papers Series, No. 02, Austin, University of Texas.

Lombardi, M. (1989): La cuestión urbana uruguaya: una nueva realidad de partida, in M. Lombardi and D. Veiga (eds.), Las ciudades en conflicto: una perspectiva latinoamericana, Montevideo, Centro de Informaciones y Estudios del Uruguay (CIESU).

Luna, J.P. (2004): La política desde el llano: conversaciones con militantes barriales, Montevideo, Ediciones de la Banda Oriental.

Massey, D. and A. Gross (1994): Migration, segregation, and the geographic concentration of poverty, American Sociological Review, vol. 59, No. 3, Washington, D.C., American Sociological Association.
Mazzei, E. and D. Veiga (1985a): Pobreza urbana en Montevideo: nueva encuesta en "Cantegriles", Cuadernos de Ciesu, No. 47, Montevideo, Ediciones de la Banda Oriental.

(1985b): Pobreza urbana en Montevideo, Montevideo, Centro de Informaciones y Estudios del Uruguay (CIESU). (1986): Una experiencia de investigación en un área de pobreza crítica de Montevideo, Revista de ciencias sociales, No. 1, Montevideo.

MEMFOD (Programa de Modernización de la Educación Media y Formación Docente) (2002): Jóvenes, educación y trabajo. Un análisis del proceso de inserción laboral en los jóvenes que han abandonado sus estudios, Cuaderno de trabajo, No. 12 Montevideo, Comisión de Transformación de la Educación Media Superior en Uruguay (TEMS).

Park, R.E. (1926): The urban community as a spatial pattern and a moral order, in E.W. Burguess and R.E. Park (eds.), The Urban Community, Chicago, University of Chicago Press.

Pellegrino, A., D. Macadar and others (2002): Proyecto segregación residencial en Montevideo: ¿un fenómeno creciente?, Montevideo, Proyecto de la Comisión Sectorial de Investigación Científica (CSIC), University of the Republic.

Portes, A. (1989): La urbanización de América Latina en los años de crisis, in M. Lombardi and D. Veiga (comps.), Las ciudades en conflicto: una perspectiva latinoamericana, Montevideo, Centro de Informaciones y Estudios del Uruguay (CIESU).

Rama, G. (1971): El club político, Montevideo, Editorial Arca.

Retamoso, A. (1999): El dinamismo poblacional del área metropolitana, Estudios sociales sobre educación, No. 8 Montevideo, National Public Education Administration (ANEP).

Rodríguez, J. and C. Arriagada (2004): Segregación residencial en la ciudad latinoamericana, Eure, vol. 29, No. 89, Santiago, Chile, Catholic University of Chile.

Sampson, R.J., J. Morenoff and T. Gannon-Rowley (2002): Assessing "neighborhood effects": social processes and new direction in research, Annual Review of Sociology, vol. 28, Palo Alto, California, Annual Reviews.

Saravi, G. (2004): Segregación urbana y espacio público: los jóvenes en enclaves de pobreza estructural, CEPAL Review, $\mathrm{N}^{\circ} 83$, LC/G.2231-P, Santiago, Chile, August.

Small, M. and K. Newman (2001), Urban poverty after the truly disadvantaged: the rediscovery of the family, the neighborhood, and culture, Annual Review of Sociology, vol. 27, Palo Alto, California, Annual Reviews.

Suárez, A.L. (2004): Inserción laboral de residentes en asentamientos urbanos del Gran Buenos Aires, document presented at the 2004 Jornadas de la Universidad Nacional de General Sarmiento, unpublished.

Svampa, M. (2002): Las nuevas urbanizaciones privadas. Sociabilidad y socialización: la integración social "hacia arriba", in S. Fieldman (ed.), Sociedad y sociabilidad en la Argentina de los 90, Buenos Aires, Biblos.

UNDP (United Nations Development Programme) (2001): Informe de desarrollo humano en Uruguay, 2001, Montevideo.

Wilson, W. 1997): When Work Disappears: The World of the New Urban Poor, New York, Vintage Books.

Zaffaroni, C. (1999): Los recursos de las familias urbanas de bajos ingresos para enfrentar situaciones críticas, in R. Kaztman (coord.), Activos y estructura de oportunidades: estudio sobre las raíces de la vulnerabilidad social en Uruguay, LC/MVD/R.180, Montevideo, ECLAC office in Montevideo. 